$4-1-2016$

\title{
Future perspective and healthy lifestyle choices in adulthood
}

\author{
Carla M. Strickland-Hughes \\ University of the Pacific, cstricklandhughes@pacific.edu \\ Aylin Tasdemir-Ozdes \\ Susan Bluck \\ Natalie C. Ebner \\ University of Florida, Gainesville, natalie.ebner@ufl.edu
}

Follow this and additional works at: https://scholarlycommons.pacific.edu/cop-facpres

Part of the Psychology Commons

\section{Recommended Citation}

Strickland-Hughes, C. M., Tasdemir-Ozdes, A., Bluck, S., \& Ebner, N. C. (2016). Future perspective and healthy lifestyle choices in adulthood. Paper presented at Cognitive Aging Conference in Atlanta, GA.

https://scholarlycommons.pacific.edu/cop-facpres/935 


\section{Introduction}

- Making healthy lifestyle choices is important, regardless of age!

- Consequences of healthy choices may be more long-term for younger, but more immediate for older

- Healthy lifestyles not always adopted by either age group Hwang, 2010; Pauus, 2005

- Future thinking is multidimensional and may vary according to one's place in the lifespan.

- Older compared to younger adults perceive less time left in life, expect a less healthy future, but may see their health as more important

- How does one's sense of the future help or hinder healthy lifestyle choices?

- One's place in the lifespan-and associated view of the future-should affect lifestyle choices

- Future perspective may constitute an age-differentiated influence on healthy choices

\section{Research Aims}

Aim (1) Determine age group differences in current healthy lifestyle choices. Older compared to younger adults will make healthier choices.

Aim 2 Identify age group differences in three types of future perspective. Older compared to younger adults will have less open global future time perspective $[2 \mathrm{~A}]$, less positive future health perspective [2B], and greater perceived importance of future health events [2C].

Aim 3 Determine effects of three types of future perspective on healthy lifestyle choices and whether such effects are moderated by age. Healthy choices will be explained by more open global future time perspective (older only) [3A], more positive future health perspective (older only) [3B], and greater perceived future importance (younger and older) [3C]

\section{Methods}

\section{Participants}

- Young: $n=78, M=19.9$ yrs., $S D=2.6$ yrs., range: $18-34$ yrs., $53 \%$ female

- Old: $n=49, M=73.2$ yrs., $S D=9.1$ yrs., range: $60-93$ yrs., $54 \%$ female

Measures

- Healthy lifestyle choices*: Choice to engage in specific healthy lifestyle activities in next two weeks, assuming busy time period; mean of 16 choices, scale $1=$ not at all likely to $4=$ very likely

- Example activities for choices: Visit with friends, eat fried food, stay active, rush through day

- Global future time perspective (FTP): 10-item FTP; how open-ended and full of opportunity one perceives one's overall future; e.g., Many opportunities still lie ahead of me.; $\alpha=.93$

- Future health perspective: 3 -items from MIDUS; perceived overall physical health, emotional health, and fitness level five years in the future; $\alpha=.80$ Macathur \& Macathur, 1998; Slaudinger etal. 2003

- Perceived future importance ${ }^{*}$ : Importance ratings, 16 specific future health-related events, $\alpha=.72$ * From Healthy Lifestyle Choices Task: mental time travel for specific lifestyle items before ratings

\section{Results}

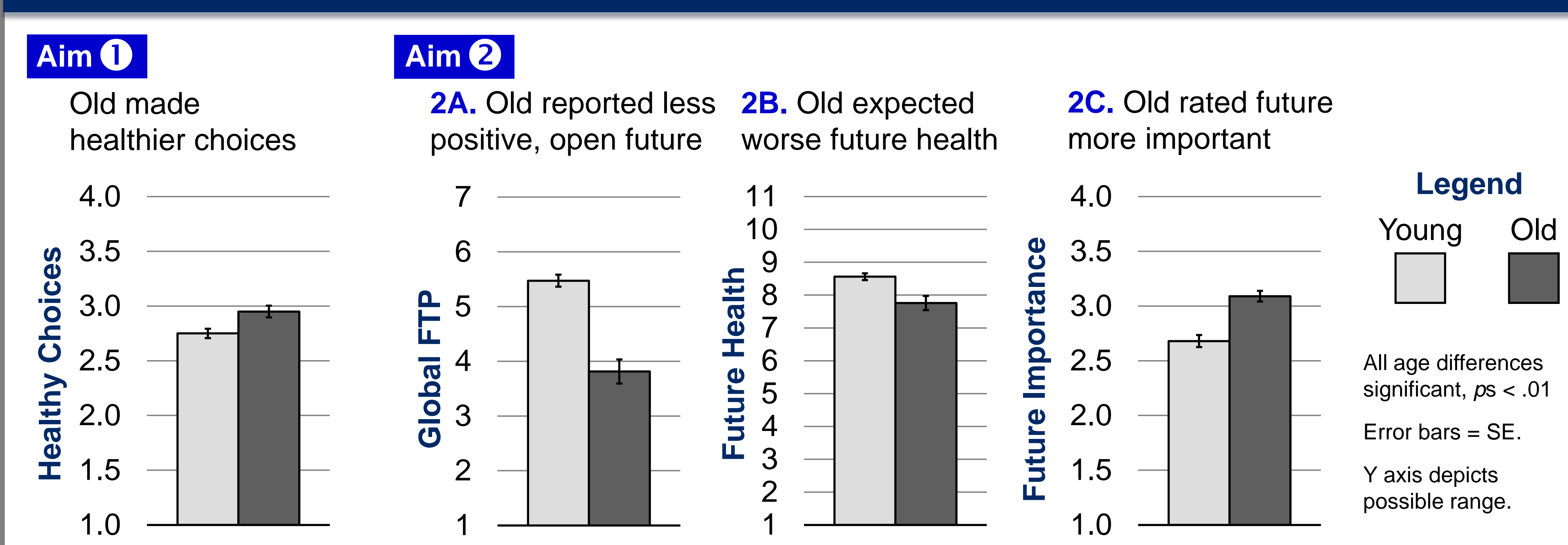

\section{Aim 3}

Multiple linear hierarchical regression predicting healthy choices

\begin{tabular}{|c|c|c|}
\hline & $B S E E$ & $\beta$ \\
\hline (Constant) & 1.01 .26 & \\
\hline Age & $.28 \quad .09$ & $35^{\star *}$ \\
\hline Global FTP & .03 & 16 \\
\hline Future Health & .03 12.12. & $.36^{* \star *}$ \\
\hline Future Importance & . 07 18 & $.23^{*}$ \\
\hline Age $\times$ Global FTP & .03 .06 & .04 \\
\hline Age $\times$ Future Health & $-.06 \quad .06$ & -.08 \\
\hline Age $\times$ Future Importance & e $-.26 \quad .18$ & -.12 \\
\hline
\end{tabular}

Multiple mediation model testing indirect effects of global FTP on healthy choices through future health and future importance

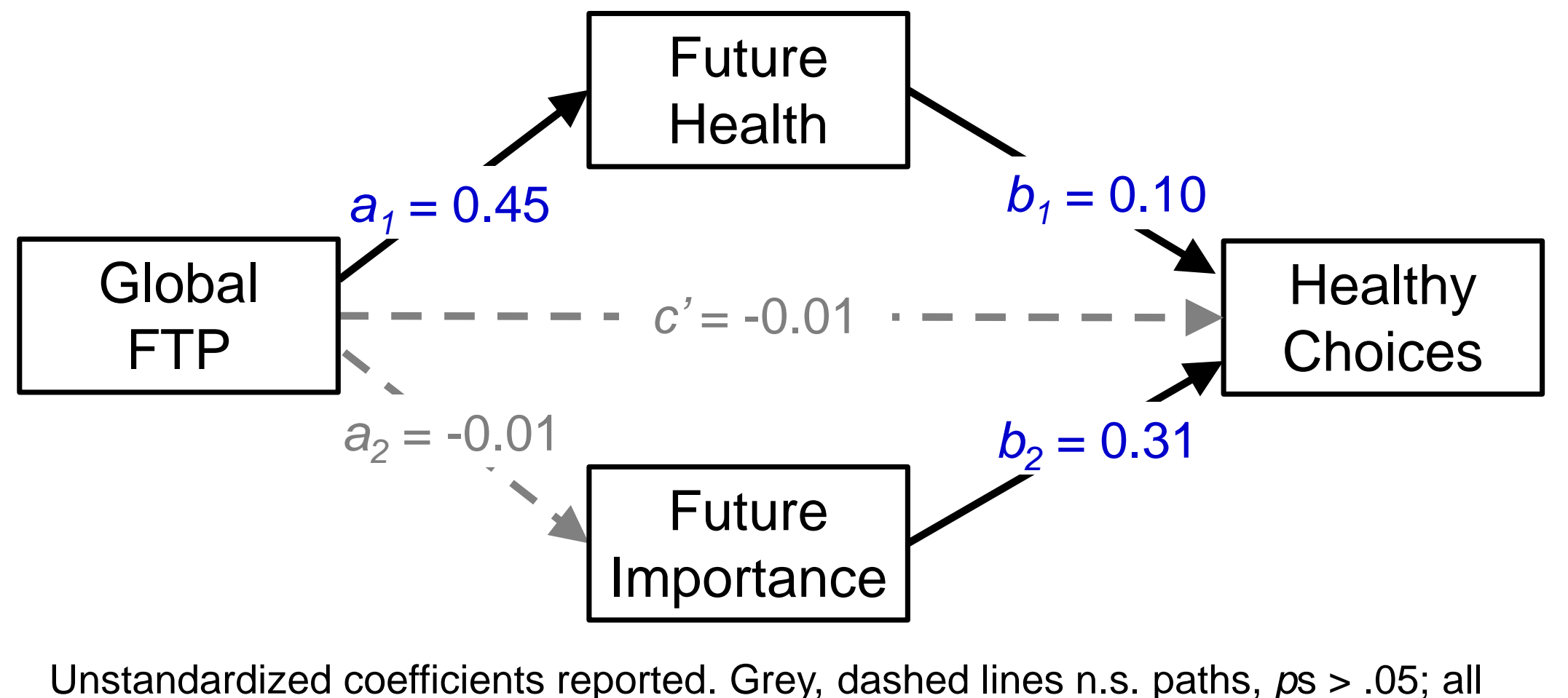

Unstandardized coeffict

3A. Direct effect of global FTP on healthy choices n.s. for both ages; but indirectly affected choices via future health

- More positive global FTP $\rightarrow$ better future health $\rightarrow$ more healthy choices

3B. More positive future health perspective related to greater tendency to make healthy choices for old and young 3C. Greater perceived future importance related to greater tendency to make healthy choices for old and young

\section{Discussion}

Young and old differed in healthy lifestyle choices and multidimensional future perspective: Old make healthier choices, perceive a less expansive future, and anticipate worse health, but view future as more important. Future perspective was linked to everyday healthy lifestyle choices in adulthood: Important beliefs for selfregulation of healthy choices are I can do this-I expect positive health! and This is important!

Age-differential intervention approaches recommended: Younger adults' healthy choices may benefit from their positive perception of future health, but they need to see future as more important. Older adults' healthy choices may benefit from the great importance they place on specific future events, but need more positive expectations. 